\title{
HKCV Rheological Constitutive Model of Mudstone under Dry and Saturated Conditions
}

\author{
Xingang Wang, ${ }^{1,2}$ Lei Huang $\mathbb{D}^{3},{ }^{3}$ Changbin Yan $\mathbb{D D}^{4},{ }^{4}$ and Baoqin Lian ${ }^{2}$ \\ ${ }^{1}$ State Key Laboratory of Continental Dynamics, Department of Geology, Northwest University, Xi'an, Shanxi 710069, China \\ ${ }^{2}$ Key Laboratory of Western China's Mineral Resource and Geological Engineering of Ministry of Education, \\ School of Geology Engineering and Surveying, Chang'an University, Xi'an, Shanxi 710054, China \\ ${ }^{3}$ Department of Engineering Geology and Geotechnical Engineering, Faculty of Engineering, China University of Geosciences, \\ Wuhan, Hubei 430074, China \\ ${ }^{4}$ School of Civil Engineering, Zhengzhou University, Zhengzhou, Henan 450001, China
}

Correspondence should be addressed to Lei Huang; huanglei@cug.edu.cn and Changbin Yan; yanchangbin@zzu.edu.cn

Received 23 December 2017; Accepted 11 February 2018; Published 1 April 2018

Academic Editor: Yixian Wang

Copyright $(2018$ Xingang Wang et al. This is an open access article distributed under the Creative Commons Attribution License, which permits unrestricted use, distribution, and reproduction in any medium, provided the original work is properly cited.

Triaxial rheological tests are performed on mudstones collected from the soft interlayer in the Three Gorges Reservoir Area. In the tests, both dry and saturated conditions are considered, and a complete rheological process is then observed. Based on such laboratory observations of stress-strain, a four-element rheological constitutive model is developed, which is composed of (i) the Hook element, (ii) the Kelvin element, (iii) the viscoelastic-plastic body, and (iv) the nonlinear viscous body (HKCV model). The HKCV model adopts the one-dimensional and three-dimensional equations that are derived. The rheological parameters required are identified, allowing the successful development of the HKCV model. A comparison with the laboratory test observations and the existing model estimates shows that the estimates of the HKCV model are relatively consistent with the observations of the triaxial rheological test. The HKCV model better characterizes the rheological process than the three existing models. However, the HKCV model has the limitation of requiring more parameters than the existing models.

\section{Introduction}

Many rocks involve moisture [1]. Moisture has multiple effects on a rock, such as softening and lubrication $[2,3]$. Moisture-dependent rheological deformation is found in many rock masses $[4,5]$, where the long-term effect of moisture aggravates the rheological properties of rocks [6], causes changes in the physical properties and microstructure of rocks, and, in turn, results in rock strength reduction or damage $[7,8]$. A significant example of this effect is that of the rock mass in the Three Gorges Reservoir Area [9]. According to incomplete statistics, approximately $69 \%$ of the reservoir area suffered rockslide hazard during the impoundment of the Three Gorges Reservoir $[10,11]$, which is closely related to the rheological effect under water-rock interaction of the mudstone formation.

Rheological mechanical characteristics have attracted extensive research. For instance, Lipponen et al. [12] studied the effect of water on the long-term stability of the tunnel surrounding the rock. Okubo et al. [13] performed a longterm creep test on aqueous tuff. A triaxial creep experiment was conducted on limestone under saturated condition [14]. A creep constitutive model was proposed to describe the deterioration of the hydraulic properties of sandstone [15]. The mechanism of creep damage under water-rock interaction of red-bed soft rock was also clarified [11]. Despite numerous rheological constitutive models for multiple types of rock $[15,16,17]$, a special model for mudstone, considering moisture content, is still required.

This paper aims to develop a new rheological constitutive model of mudstone, which allows the incorporation of the effect of moisture. First, the laboratory triaxial rheological tests are conducted on the mudstone specimens collected from the interlayer in the Three Gorges Reservoir Area. Both dry and saturated conditions are considered. Based on these test observations of stress-strain, a rheological constitutive 


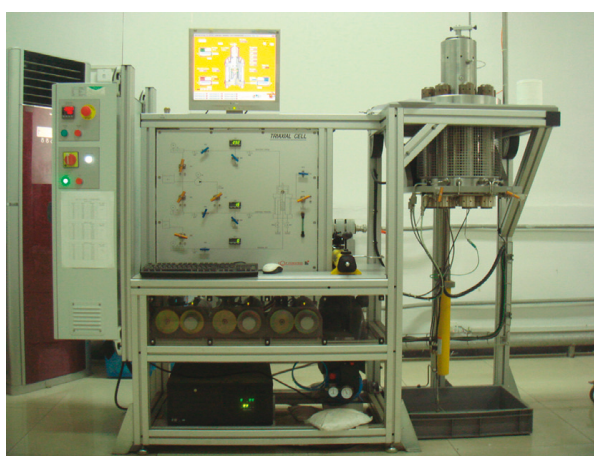

(a)

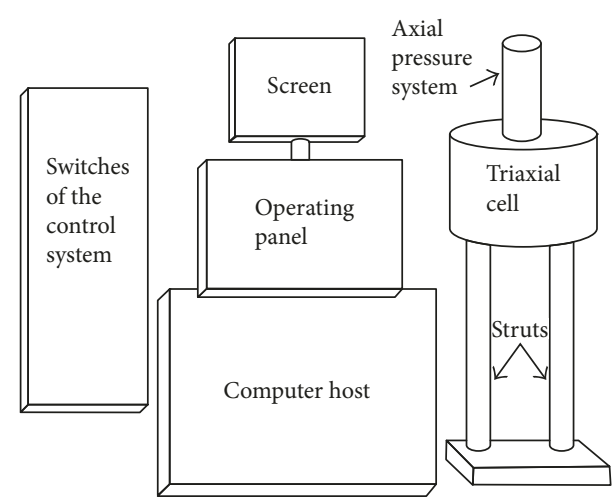

(b)

Figure 1: Triaxial rheological instrument. (a) Photograph. (b) Schematic diagram.

TABLE 1: Level of axial load.

\begin{tabular}{lcccccccc}
\hline Condition & $\begin{array}{c}\text { Density } \\
\left(\mathrm{g} / \mathrm{cm}^{3}\right)\end{array}$ & $\begin{array}{c}\text { Longitudinal wave } \\
\text { velocity }(\mathrm{m} / \mathrm{s})\end{array}$ & First stage & Second stage & Third stage & Fourth stage & Fifth stage & Sixth stage \\
\hline Dry & 2.47 & 2931 & 10 & 20 & 30 & 35 & 40 \\
Saturated & 2.71 & 2986 & 10 & 20 & 30 & 35 & 45 \\
\hline
\end{tabular}

model, namely, the HKCV model, is then developed. Finally, the developed model estimates are compared with the laboratory test observations and the existing model estimates.

\section{Test Equipment and Method}

2.1. Test Equipment. The triaxial rheological test equipment is a rock triaxial rheometer (Figure 1), which consists of (1) a control system, (2) an oil source, (3) an axial pressure system, (4) a confining pressure system, (5) a seepage system, (6) a temperature system, and (7) sensors. The sensors include those for measuring (a) deformation, (b) load, (c) pressure, and (d) temperature. For the axial and lateral deformation, we used LVDT and ring deformation sensors, respectively.

2.2. Test Method. Mudstone specimens used for the rheological tests were collected from the soft interlayer in the Majiagou landslide in the Three Gorges Reservoir Area, China. Standard sizes with diameters of $50 \mathrm{~mm}$ and lengths of $100 \mathrm{~mm}$ were prepared.

Complete saturation is accomplished by means of vacuum saturation equipment, using the following procedure:

(i) Dry the rock specimens for 12 hours (h) in a dryer, and then cool down naturally

(ii) Saturate the specimens in a sealed container, using distilled water

(iii) Use a vacuum pump to extract air from the container in order to create a vacuum

(iv) Maintain the negative air pressure of $0.1 \mathrm{MPa}$ for $24 \mathrm{~h}$.

Although the degree of saturation was not measured in the current work, much previous literature, such as $[18,19]$, has experimentally proven that such a saturation method allows complete saturation.
The seepage system at the bottom of the triaxial cell controls the maintenance of the saturated condition of rock specimens during tests. The confining pressure used in the rheological tests is $3 \mathrm{MPa}$, which is close to the in situ pressure of the rock. Axial load is applied level by level, according to the results of the conventional triaxial compression tests (Table 1 ). If the deformation rate is no more than $0.001 \mathrm{~mm} / 24 \mathrm{~h}$ for $72 \mathrm{~h}$, then the rheological deformation is recognized to be stable, and the next level of axial load can be applied.

2.3. Test Results. Strain-time curves for the whole process of rheological deformation are obtained from the tests, as shown in Figure 2 (for dry condition) and Figure 3 (for saturated condition).

The following findings are drawn from Figures 2 and 3:

(1) Each time the axial load is applied, the instantaneous elastic strain is produced.

(2) Under low axial load, the axial strain rate begins to decrease, and after a short time, the strain levels off.

(3) Under high axial load, the axial strain experiences continuous accumulation, and the strain rate is greater than zero. Once the strain accumulation exceeds a critical value, mudstone rapidly enters the accelerated rheological stage, until rheological failure.

Interestingly, the volumetric strain appeared to increase at the beginning of the $10 \mathrm{MPa}$ pressure application. As is well known, volumetric strain occurs as a result of two opposite factors: (a) radial expansion, which contributes to the increase of volumetric strain, and (b) axial shrink, which contributes to the decrease of volumetric strain. A possible reason for such volumetric strain increase is that the contribution of radial expansion exceeds that of axial shrink. 


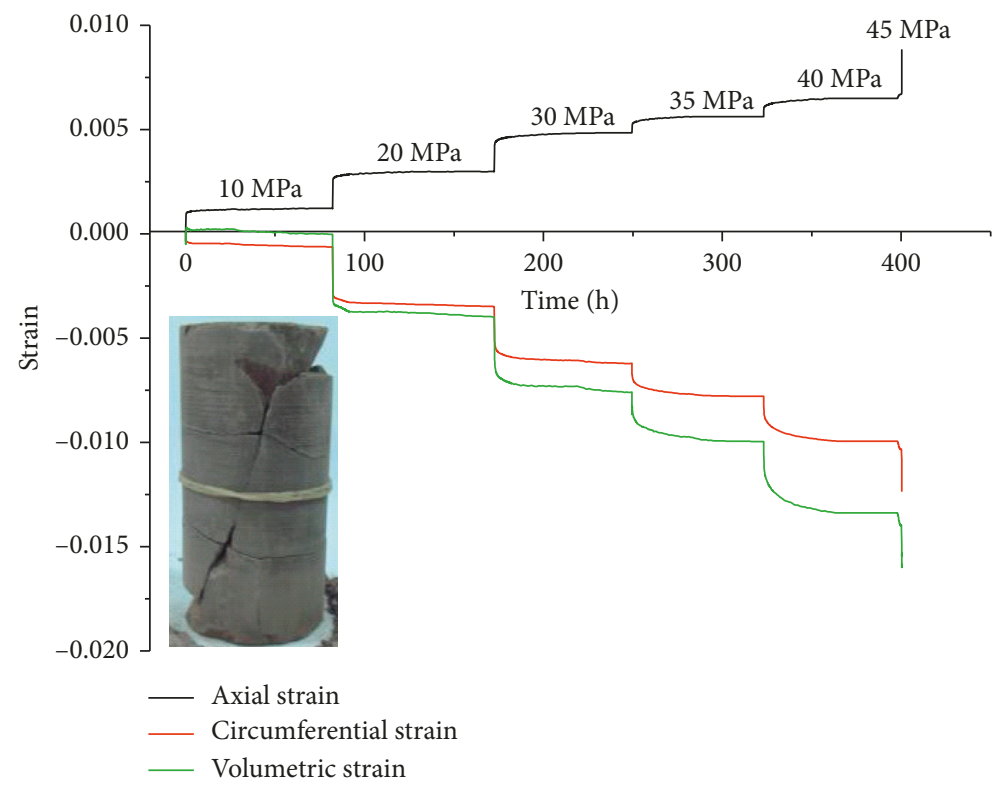

Figure 2: Strain of mudstone over time (under dry condition).

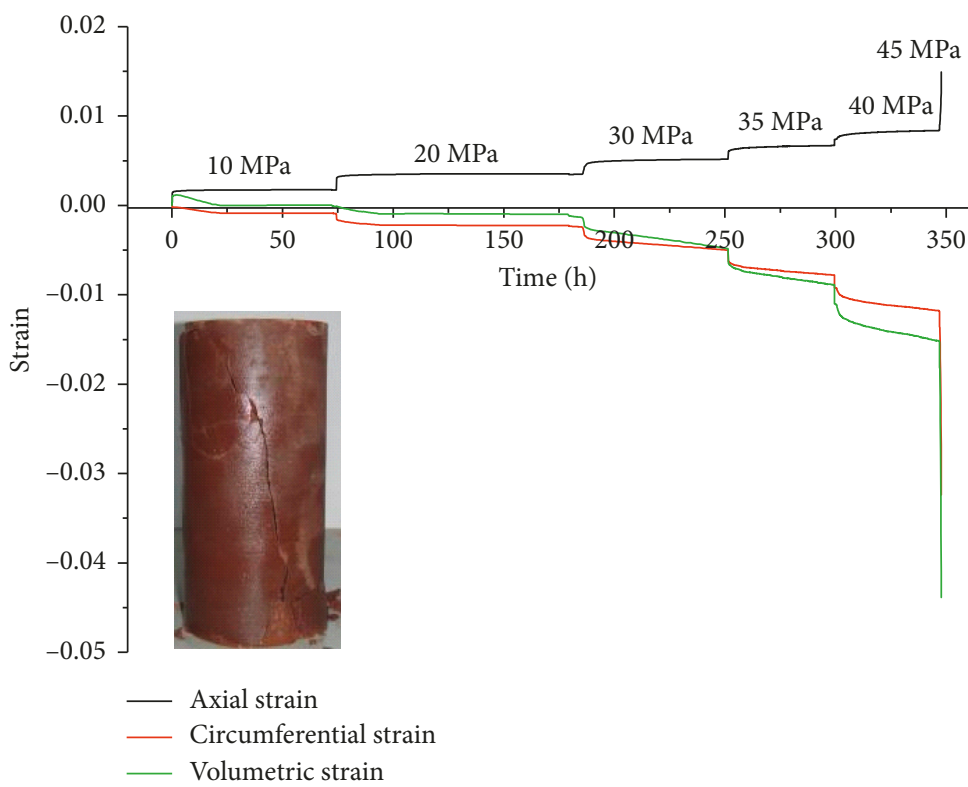

FIgURE 3: Strain of mudstone over time (under saturated condition).

Consequently, the volumetric strain, as an overall measure of deformation, increased.

Figures 4 and 5 show the axial strain and strain rate over time, for dry and saturated conditions, respectively. They are obtained after the application of the last level of axial load (45 MPa). As shown in Figures 4 and 5, before final failure, the mudstone experiences three typical rheological stages, namely: (1) a decelerated rheological stage, (2) a stable rheological stage, and (3) an accelerated rheological stage. During the decelerated rheological stage, the strain continuously accumulates, and the accumulation gradually increases, but the strain increase rate reduces continuously, that is, $\varepsilon>0, \dot{\varepsilon}>0$, and $\ddot{\varepsilon}<0$. During the stable rheological stage, the strain continuously accumulates over time, but the strain increase rate is constant, that is, $\varepsilon>0, \dot{\varepsilon}>0$, and $\ddot{\varepsilon}=0$. During the accelerated rheological stage, the strain develops rapidly, and the strain increase rate shows a trend of increase, that is, $\varepsilon>0, \dot{\varepsilon}>0$, and $\ddot{\varepsilon}>0$. Since $t_{\mathrm{P}}$, microcracks and pores in the rock specimens propagate, converge, and get connected, leading to final failure at the time point of $t_{\mathrm{F}}$.

Table 2 lists the increment values of total strain (comprising instantaneous strain and rheological strain) under each level of axial load. As shown in this table, under the same level of axial load, both the values of total axial and circumferential strains of saturated mudstone are greater than those of dry mudstone. The total cumulative axial strain 


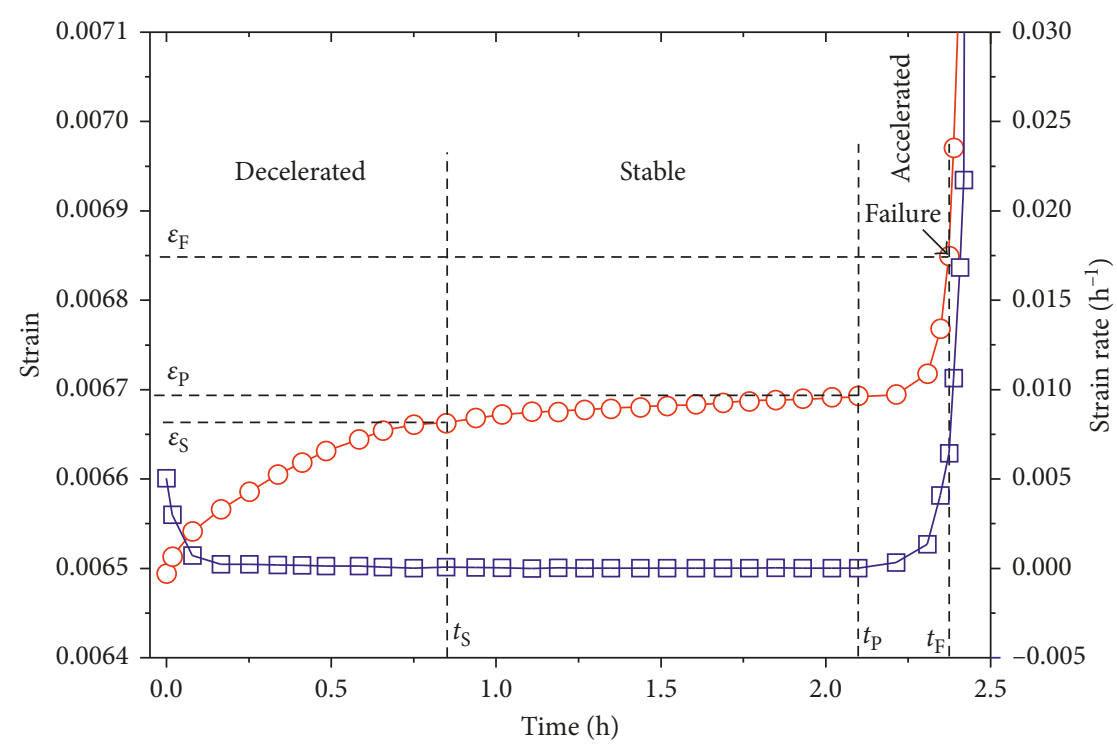

FIGURE 4: Strain of mudstone and strain rate over time (under dry condition). $t_{\mathrm{S}}$ is the time point when the rock specimens enter the stable rheological stage from the decelerated rheological stage. $\varepsilon_{\mathrm{S}}$ is the strain value at this moment. $t_{\mathrm{P}}$ is the time point when the rock specimens enter the accelerated rheological stage from the stable rheological stage. $\varepsilon_{\mathrm{P}}$ is the strain value at the boundary point between the stable rheological stage and the accelerated rheological stage. $t_{\mathrm{F}}$ is the time point when the final failure of rock specimens occurs. $\varepsilon_{\mathrm{F}}$ is the strain value at the time of failure.

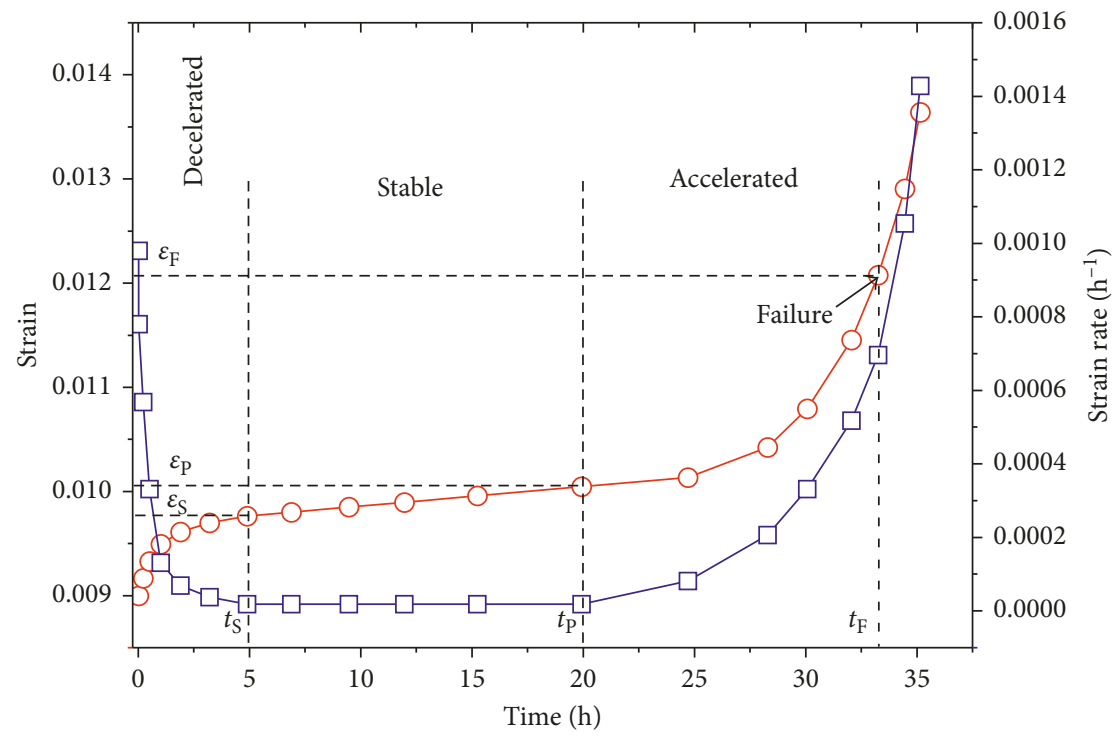

FIGURE 5: Strain of mudstone and strain rate over time (under saturated condition).

of saturated mudstone before failure is $0.143,168 \%$ larger than that of dry mudstone, which is 0.085 . The total cumulative circumferential strain of saturated mudstone before failure is $0.409,371 \%$ larger than that of dry mudstone, which is 0.110 . The total cumulative volumetric strain of saturated mudstone before failure is 0.675 , $503 \%$ larger than that of dry mudstone, which is 0.134 . An interpretation for such phenomena is that water seepage through the microcracks of saturated mudstone softens the mudstone, thus reducing the mudstone strength and relatively increasing the total strain of the mudstone in each direction. Comparison with previous literature such as [20] shows that the different sampling positions or loading methods would produce different test results.

Figure 6 shows $\Delta \varepsilon_{1} / \Delta \varepsilon_{2}$ and $\Delta \varepsilon_{1} / \Delta \varepsilon_{\mathrm{v}}$ against axial load, for both dry and saturated conditions. As axial load increases, the increase rates of circumferential and volumetric strains gradually exceed the increase rate of axial strain, and eventually the rock deformation shifts to volumetric expansion from volumetric compression. Under the same level of axial load, the saturated mudstone undergoes higher circumferential and volumetric strains than in the dry condition, suggesting that mudstone under the long-term effect of water is prone to more significant circumferential and volumetric expansions. 


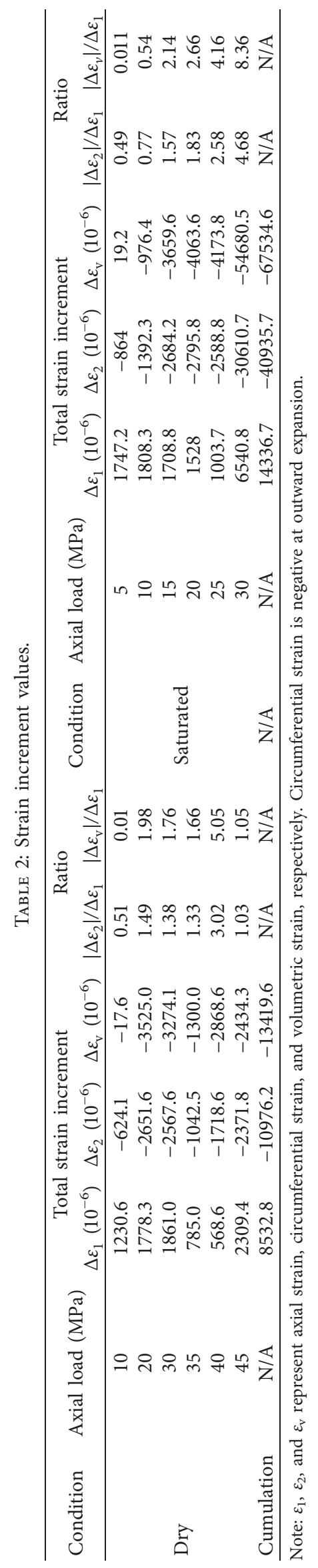




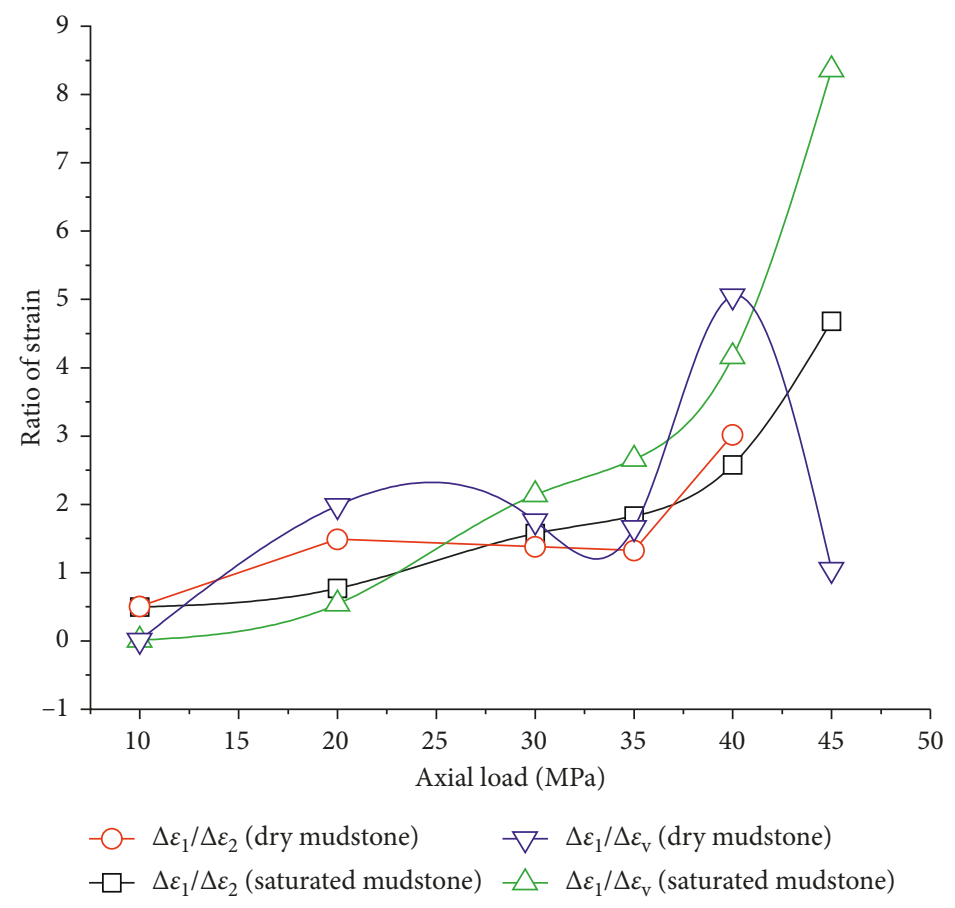

FIGURE 6: Ratio of strain against axial load.

\section{The Developed HKCV Rheological Constitutive Model}

Previous rheological constitutive models for rocks fall into three major categories: (1) empirical models, (2) rheological models based on damage mechanism, and (3) element models. The element models describe the elastic, plastic, viscoelastic, viscoplastic, and other rheological mechanical characteristics of rock and soil by combining the Hookean solid (H), Newtonian fluid (N), St. Venant solid (S), and so on.

Generally, elasticity, plasticity, viscoelasticity, and viscoplasticity coexist in soft rocks such as mudstone [21]. As revealed in Figures 2 and 3, the mudstone has instantaneous elastic strain at the beginning of shear stress application, suggesting that the rheological element model for mudstone contains an independent elastic element. After instantaneous deformation, their strain gradually increases and gradually levels off under low axial load, suggesting that the constitutive model for mudstone should contain a viscous element which is combined with the elastic element. Under high axial load, the strain increases continually, suggesting that the rheological model for mudstone should contain a plastic element. During the accelerated rheological stage, the strain accelerates and shows a nonlinear feature, suggesting that the model should contain a nonlinear viscous element.

Based on the above analysis, a rheological element combination model consisting of the Hook element, the Kelvin element, the viscoelastic-plastic body, and the nonlinear viscous body connected in series (referred to as $\mathrm{HKCV}$ model) is proposed. It is used as the rheological model for the mudstone to describe the nonlinear viscoelastic-plastic feature (Figure 7). In this model, a nonlinear Newtonian fluid is introduced as the element of the nonlinear viscous

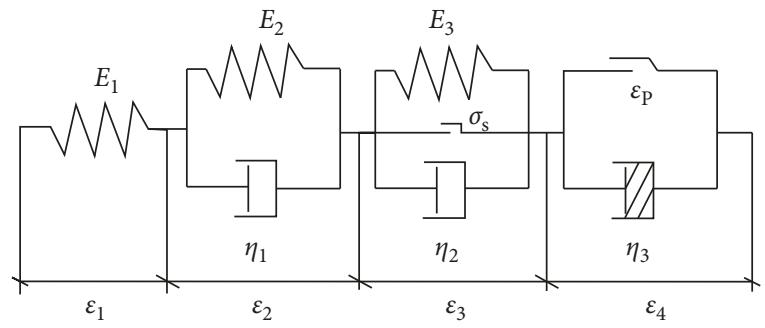

FIgURE 7: HKCV model. $E_{1}$ is the instantaneous elastic modulus. $E_{2}$ and $E_{3}$ are the viscoelastic moduli. $\eta_{1}, \eta_{2}$, and $\eta_{3}$ are the viscoelastic coefficients. $\varepsilon_{1}, \varepsilon_{2}, \varepsilon_{3}$, and $\varepsilon_{4}$ are the strains corresponding to the rheological bodies. $\sigma_{\mathrm{S}}$ is the yield stress of rock. $\varepsilon_{\mathrm{P}}$ is the strain value at the boundary point between the stable rheological stage and the accelerated rheological stage.

body, which is necessary for accurate description of the accelerated rheological stage.

The constitutive equation for Newtonian fluid is written as

$$
\varepsilon=\frac{\sigma}{\eta(t)}
$$

where $\eta(t)$ is a time function of viscosity coefficient $\eta$.

Let $\eta(t)=\eta_{3}(t-a)^{2}$, where $\eta_{3}$ is the initial viscosity coefficient during the accelerated rheological deformation. $a$ is the characteristic value determined by fitting the rheological test curve. Then, $\eta$ is expressed as

$$
\eta(t)=\eta_{3}(t-a)^{2}=\frac{\eta_{3}(t-a)^{2}}{t_{0}^{2}},
$$

where $t_{0}$ is the unit reference time, which is set to 1 .

Accordingly, the constitutive equation for the element of the nonlinear viscous body in the HKCV model is rewritten as 


$$
\varepsilon(t)= \begin{cases}0, & \text { if } \varepsilon<\varepsilon_{\mathrm{P}} \\ \frac{\sigma}{\eta_{3}(t-a)^{2} / t_{0}^{2}}=\frac{\sigma}{\eta_{3}(t-a)^{2}}, & \text { if } \varepsilon \geq \varepsilon_{\mathrm{P}}\end{cases}
$$

3.1. One-Dimensional Rheological Equation for $\mathrm{HKCV}$ Model. Three cases are involved:

(1) If $\sigma<\sigma_{s}$ and $\varepsilon<\varepsilon_{\mathrm{P}}$, keeping $\sigma=\sigma_{0}=$ constant, and carrying out Laplace and inverse Laplace transforms, then the rheological equation for the HKCV model is obtained as follows:

$$
\varepsilon(t)=\frac{\sigma_{0}}{E_{1}}+\frac{\sigma_{0}}{E_{2}}\left(1-e^{-\left(E_{2} / \eta_{1}\right) t}\right) .
$$

(2) If $\sigma_{0} \geq \sigma_{\mathrm{s}}$ and $\varepsilon<\varepsilon_{\mathrm{P}}$, then the rheological equation for the HKCV model is

$$
\varepsilon(t)=\frac{\sigma_{0}}{E_{1}}+\frac{\sigma_{0}}{E_{2}}\left(1-e^{-\left(E_{2} / \eta_{1}\right) t}\right)+\frac{\sigma_{0}-\sigma_{S}}{E_{3}}\left(1-e^{-\left(E_{3} / \eta_{2}\right) t}\right) .
$$

(2) If $\sigma_{0} \geq \sigma_{\mathrm{s}}$ and $\varepsilon \geq \varepsilon_{\mathrm{p}}$, then the rheological equation for the HKCV model is

$$
\begin{aligned}
\mathcal{\varepsilon}(t)= & \frac{\sigma_{0}}{E_{1}}+\frac{\sigma_{0}}{E_{2}}\left(1-e^{-\left(E_{2} / \eta_{1}\right) t}\right) \\
& +\frac{\sigma_{0}-\sigma_{\mathrm{S}}}{E_{3}}\left(1-e^{-\left(E_{3} / \eta_{2}\right) t}\right)+\frac{\sigma_{0}(t-a)^{-2}}{\eta_{3}} .
\end{aligned}
$$

3.2. Three-Dimensional Rheological Equation for $H K C V$ Model. In a three-dimensional stress state, let the spherical stress tensor in rocks be $\sigma_{\mathrm{m}}$, the deviatoric stress tensor be $S_{i j}$, the Kronecker symbol be $\delta_{i j}$, the spherical strain tensor be $\varepsilon_{\mathrm{m}}$, the deviatoric strain tensor be $e_{i j}$, the shear modulus of rocks be $G$, and the bulk modulus be $K$. Assuming that the bulk modulus keeps constant in the rheological process and is equal to the bulk modulus $K$ during elastic deformation, the rheological equation for the HKCV model in a threedimensional stress state can be obtained, as formulated below:

$$
\varepsilon_{i j}= \begin{cases}\frac{\left(S_{i j}\right)_{0}}{2 G_{1}}+\frac{\sigma_{\mathrm{m}} \delta_{i j}}{3 K}+\frac{\left(S_{i j}\right)_{0}}{2 G_{2}}\left(1-e^{-\left(G_{2} / \eta_{1}\right) t}\right), & \text { if }\left(S_{i j}\right)_{0}<\sigma_{\mathrm{s}}, \varepsilon_{i j}<\varepsilon_{\mathrm{P}} \\ \frac{\left(S_{i j}\right)_{0}}{2 G_{1}}+\frac{\left(S_{i j}\right)_{0}}{2 G_{2}}\left(1-e^{-\left(G_{2} / \eta_{1}\right) t}\right)+\frac{\sigma_{\mathrm{m}} \delta_{i j}}{3 K}+\frac{\left(S_{i j}\right)_{0}-\sigma_{\mathrm{S}}}{2 G_{3}}\left(1-e^{-\left(G_{3} / \eta_{2}\right) t}\right), & \text { if }\left(S_{i j}\right)_{0} \geq \sigma_{\mathrm{S}}, \varepsilon_{i j}<\varepsilon_{\mathrm{P}} \\ \frac{\left(S_{i j}\right)_{0}}{2 G_{1}}+\frac{\left(S_{i j}\right)_{0}}{2 G_{2}}\left(1-e^{-\left(G_{2} / \eta_{1}\right) t}\right)+\frac{\sigma_{\mathrm{m}} \delta_{i j}}{3 K}+\frac{\left(S_{i j}\right)_{0}-\sigma_{\mathrm{S}}}{2 G_{3}}\left(1-e^{-\left(G_{3} / \eta_{2}\right) t}\right)+\frac{\left(S_{i j}\right)_{0}}{2 \eta_{3}(t-a)^{2}}, & \text { if }\left(S_{i j}\right)_{0} \geq \sigma_{\mathrm{S}}, \varepsilon_{i j} \geq \varepsilon_{\mathrm{P}} .\end{cases}
$$

\section{Comparison with the Observation of Test and the Estimates of Existing Models}

In the test, the rheological stress state under triaxial compression is $\sigma_{2}=\sigma_{3}$ and keeps constant. Each level of load $\sigma_{1}$ is also constant after application. Hence, the rheological equation for the HKCV model in this situation can be rewritten as follows:

$$
\varepsilon_{11}= \begin{cases}\frac{\sigma_{1}+2 \sigma_{3}}{9 K}+\frac{\sigma_{1}-\sigma_{3}}{3 G_{1}}+\frac{\sigma_{1}-\sigma_{3}}{3 G_{2}}\left(1-e^{-\left(G_{2} / \eta_{1}\right) t}\right), & \text { if }\left(\sigma_{1}-\sigma_{3}\right)<\sigma_{\mathrm{S}} \\ \frac{\sigma_{1}+2 \sigma_{3}}{9 K}+\frac{\sigma_{1}-\sigma_{3}}{3 G_{1}}+\frac{\sigma_{1}-\sigma_{3}}{3 G_{2}}\left(1-e^{-\left(G_{2} / \eta_{1}\right) t}\right)+\frac{\sigma_{1}-\sigma_{3}-\sigma_{\mathrm{S}}}{3 G_{3}}\left(1-e^{-\left(G_{3} / \eta_{2}\right) t}\right), & \text { if }\left(\sigma_{1}-\sigma_{3}\right) \geq \sigma_{\mathrm{S}}, \varepsilon<\varepsilon_{\mathrm{P}} \\ \frac{\sigma_{1}+2 \sigma_{3}}{9 K}+\frac{\sigma_{1}-\sigma_{3}}{3 G_{1}}+\frac{\sigma_{1}-\sigma_{3}}{3 G_{2}}\left(1-e^{-\left(G_{2} / \eta_{1}\right) t}\right)+\frac{\sigma_{1}-\sigma_{3}-\sigma_{\mathrm{S}}}{3 G_{3}}\left(1-e^{-\left(G_{3} / \eta_{2}\right) t}\right)+\frac{\sigma_{1}-\sigma_{3}}{3 \eta_{3}(t-a)^{2}}, & \text { if }\left(\sigma_{1}-\sigma_{3}\right) \geq \sigma_{\mathrm{S}}, \varepsilon \geq \varepsilon_{\mathrm{P}} .\end{cases}
$$


TABLE 3: Rheological parameters required for the HKCV model.

\begin{tabular}{lcccccccc}
\hline Condition & Axial load $(\mathrm{MPa})$ & $G_{1}(\mathrm{GPa})$ & $G_{2}(\mathrm{GPa})$ & $G_{3}(\mathrm{GPa})$ & $\eta_{1}(\mathrm{GPa} \cdot \mathrm{h})$ & $\eta_{2}(\mathrm{GPa} \cdot \mathrm{h})$ & $\eta_{3}(\mathrm{GPa} \cdot \mathrm{h})$ & $a$ \\
\hline Dry & 45 & 2.36 & 77.22 & 30.353 & 5.42 & 3.79 & 285.27 & 2.43 \\
Saturated & 45 & 1.70 & 13.12 & 444.04 & 2.64 & 2.01 & 91.13 & 40.8 \\
\hline
\end{tabular}

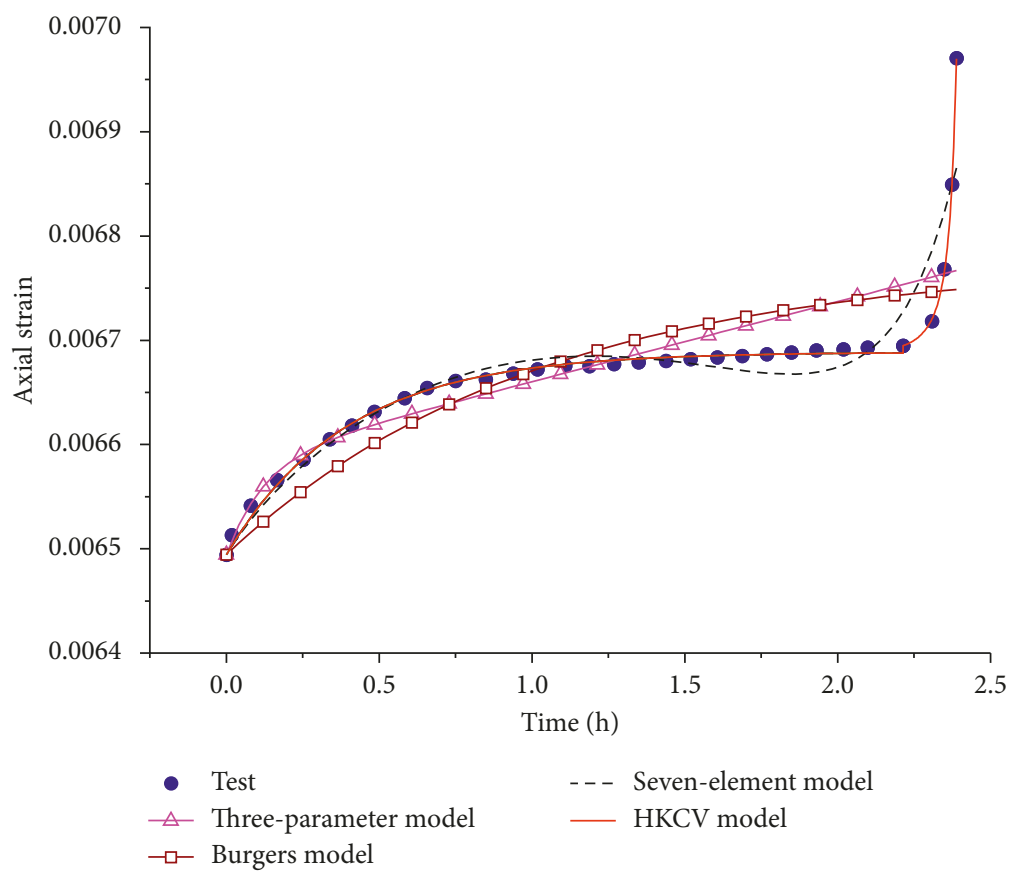

Figure 8: Comparison between test value and model values (under dry condition, $\sigma_{1}=45 \mathrm{MPa}$ ).

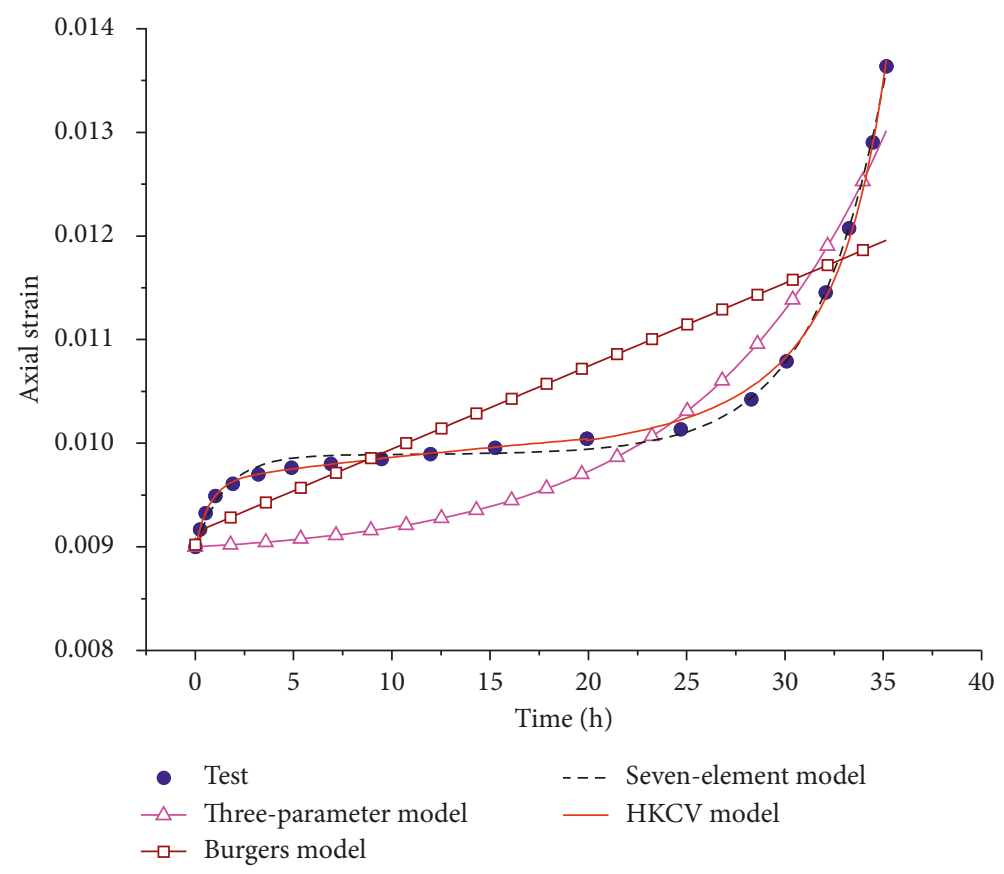

Figure 9: Comparison between test value and model values (under saturated condition, $\sigma_{1}=35 \mathrm{MPa}$ ). 
The triaxial rheological test curves of the mudstone under dry and saturated conditions were processed with the Boltzmann superposition principle. The results of parameter identification are shown in Table 3.

Take the axial strain-time curves of dry and saturated mudstone after the application of the last level of axial load as an example. The HKCV model was compared with the H-K three-component model [22, 23], the Burgers model [24, 25], the seven-element model $[5,26]$, and the test observation (Figures 8 and 9). Comparison between the HKCV model estimate and the test observation shows that the HKCV model estimate is relatively consistent with the triaxial rheological test observation, demonstrating that the proposed HKCV model allows accurate description for the rheological process of the mudstone. Comparison between the HKCV model estimate and the three existing models shows that the HKCV model fits the test observation better than the three existing models, revealing more accurate description. However, it should be noted that the HKCV model has the limitation of requiring more parameters than the three existing models.

\section{Conclusion}

The developed HKCV model of mudstone closely matches the laboratory triaxial rheological test observations. The HKCV model better characterizes the rheological process of mudstone than the three existing models, namely, the threeparameter model, the Burgers model, and the seven-element model. However, the HKCV model has the limitation of requiring more parameters than the existing models.

\section{Conflicts of Interest}

The authors declare that there are no conflicts of interest regarding the publication of this article.

\section{Acknowledgments}

This research was financially supported by the Scientific Research Program, funded by Shaanxi Provincial Education Department (Grant no. 16JK1766), the Open Foundation of Jiangxi Engineering Research Center of Water Engineering Safety and Resources Efficient Utilization (Grant no. OF201602), the Postdoctoral Scientific Research Project in Shaanxi Province (Grant no. 2016BSHEDZZ31), and the National Natural Science Foundation of China (Grant no. U1504523).

\section{References}

[1] A. Gilles, C. Nathalie, T. Jean, and M. S. Darius, "Fundamental aspects of the hydromechanical behaviour of CallovoOxfordian claystone: from experimental studies to model calibration and validation," Computers and Geotechnics, vol. 85, pp. 277-286, 2017.

[2] C. Agan, "A preliminary study on the conservation and polishing performance of Sanliurfa limestones as a traditional building material," Bulletin of Engineering Geology and the Environment, vol. 75, no. 1, pp. 13-25, 2016.

[3] A. Kaya, "Geotechnical assessment of a slope stability problem in the citlakkale residential area (Giresun, NE Turkey),"
Bulletin of Engineering Geology and the Environment, vol. 76, no. 3, pp. 875-889, 2016.

[4] J. F. Shao, Q. Z. Zhu, and K. Su, "Modeling of creep in rock materials in terms of material degradation," Computers and Geotechnics, vol. 30, pp. 549-555, 2003.

[5] W. Y. Xu, R. B. Wang, W. Wang, Z. L. Zhang, J. C. Zhang, and W. Y. Wang, "Creep properties and permeability evolution in triaxial rheological tests of hard rock in dam foundation," Journal of Central South University, vol. 19, pp. 252-261, 2012.

[6] X. G. Wang, B. Hu, H. M. Tang, X. L. Hu, J. D. Wang, and L. Huang, "A constitutive model of granite shear creep under moisture," Journal of Earth Science, vol. 27, no. 4, pp. 677-685, 2016.

[7] N. Reviron, T. Reuschlé, and J.-D. Bernard, "The brittle deformation regime of water saturated siliceous sandstones," Geophysical Journal International, vol. 178, no. 3, pp. 17661778, 2009.

[8] D. Li, L. N. Y. Wong, G. Liu, and X. P. Zhang, "Influence of water content and anisotropy on the strength and deformability of low porosity meta-sedimentary rocks under triaxial compression," Engineering Geology, vol. 126, pp. 46-66, 2012.

[9] M. J. Sun, H. M. Tang, M. Y. Wang, Z. G. Shan, and X. L. Hu, "Creep behavior of slip zone soil of the Majiagou landslide in the Three Gorges area," Environmental Earth Sciences, vol. 75, no. 16, p. 1199, 2016.

[10] W. X. Jian, K. L. Yin, C. Q. Ma, and C. Zhang, "Characteristics of incompetent beds in Jurassic red clastic rocks in Wanzhou," Rock and Soil Mechanics, vol. 26, no. 6, pp. 901-905, 2005.

[11] H. F. Deng, M. L. Zhou, J. L. Li, X. S. Sun, and Y. L. Huang, "Creep degradation mechanism by water-rock interaction in the red-layer soft rock," Arabian Journal of Geosciences, vol. 9, p. 601, 2016.

[12] A. Lipponen, S. Manninen, H. Nini, and E. Rönkäa, "Effect of water and geological factors on the long-term stability of fracture zones in the Pine Tunnel, Finland: a case study," International Journal of rock mechanics and Mining Sciences, vol. 42, no. 1, pp. 3-12, 2005.

[13] S. Okubo, K. Fukui, and K. Hashiba, "Long-term creep of water-saturated tuff under uniaxial compression," International Journal of Rock Mechanics and Mining Sciences, vol. 47, no. 5, pp. 839-844, 2010.

[14] N. Brantut, M. J. Heap, P. Baud, and P. G. Meredith, "Mechanisms of time-dependent deformation in porous limestone," Journal of Geophysical Research-Solid Earth, vol. 7, pp. 5444-5463, 2014.

[15] M. C. Weng, "A generalized plasticity-based model for sandstone considering time-dependent behavior and wetting deterioration," Rock Mechanics and Rock Engineering, vol. 7, pp. 1197-1209, 2014.

[16] G. Barla, D. Debernardi, and D. Sterpi, "Time-dependent modeling of tunnels in squeezing conditions," International Journal of Geomechanics, vol. 12, no. 6, pp. 697-710, 2012.

[17] L. Z. Wu, B. Li, R. Q. Huang, and P. Sun, "Experimental study and modeling of shear rheology in sandstone with nonpersistent joints," Engineering Geology, vol. 222, pp. 201211, 2017.

[18] Z. L. Zhou, X. Cai, Y. Zhao, L. Chen, C. Xiong, and X. B. Li, "Strength characteristics of dry and saturated rock at different strain rates," Transactions of Nonferrous Metals Society of China, vol. 26, pp. 1919-1925, 2016.

[19] A. D. Haller, M. Hobbs, and J. E. Spangenberg, "Adapting the diffusive exchange method for stable isotope analysis of pore water to brine-saturated rocks," Chemical Geology, vol. 444, pp. 37-48, 2016. 
[20] Y. L. Lu, L. G. Wang, X. K. Sun, and J. Wang, "Experimental study of the influence of water and temperature on the mechanical behavior of mudstone and sandstone," Bulletin of Engineering Geology and the Environment, vol. 76, pp. 645660, 2017.

[21] X. G. Wang, J. D. Wang, T. F. Gu, and B. Q. Lian, “A modified Hoek-Brown failure criterion considering the damage to reservoir bank slope rocks under water saturationdehydration circulation," Journal of Mountain Science, vol. 14, no. 4, pp. 771-781, 2017.

[22] E. H. Rutter and S. Green, "Quantifying creep behaviour of clay-bearing rocks below the critical stress state for rapid failure: Mam Tor landslide, Derbyshire," Journal of the Geological Society, vol. 168, pp. 359-372, 2011.

[23] B. Nedjar and R. Le Roy, "An approach to the modeling of viscoelastic damage. Application to the long-term creep of gypsum rock materials," International Journal for Numerical and Analytical, vol. 37, no. 9, pp. 1066-1078, 2013.

[24] P. Nomikos, R. Rahmannejad, and A. Sofianos, "Supported axisymmetric tunnels within linear viscoelastic Burgers rocks," Rock Mechanics and Rock Engineering, vol. 44, no. 5, pp. 553-564, 2011.

[25] F. Bozzano, S. Martino, and A. Montagna, "Back analysis of a rock landslide to infer rheological parameters," Engineering Geology, vol. 131-132, pp. 45-56, 2012.

[26] W. Y. Xu, S. Q. Yang, and W. J. Chu, "Nonlinear viscoelastoplastic rheological model (Hohai model) of rock and its engineering application," Chinese Journal of Rock Mechanics and Engineering, vol. 25, no. 3, pp. 433-447, 2006. 


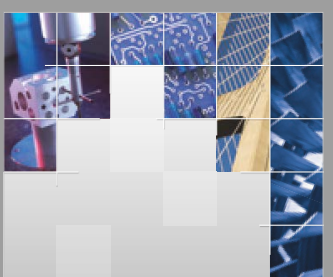

\section{Enfincering}
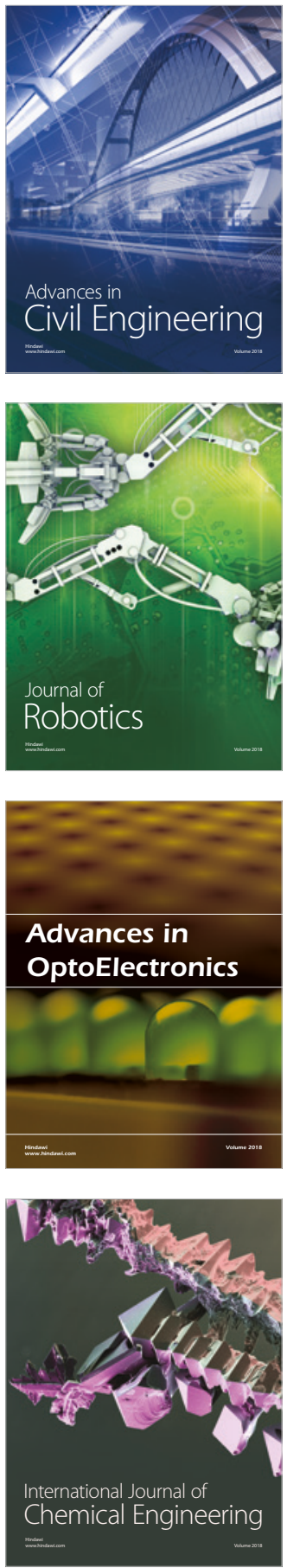

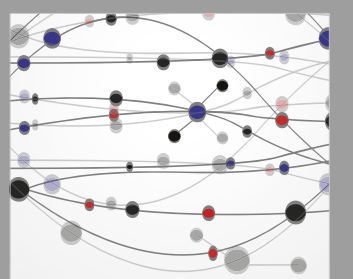

\section{Rotating \\ Machinery}

The Scientific World Journal

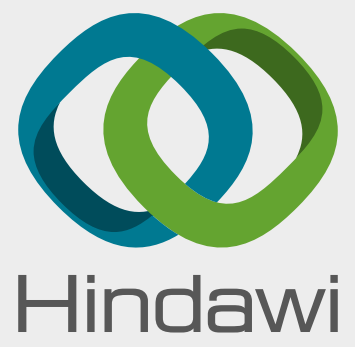

Submit your manuscripts at

www.hindawi.com
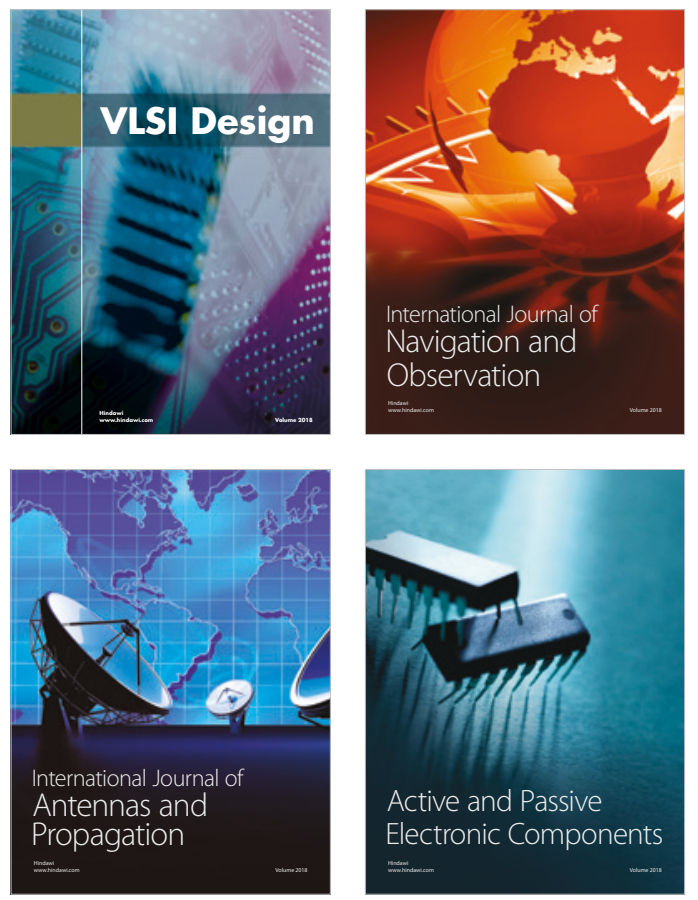
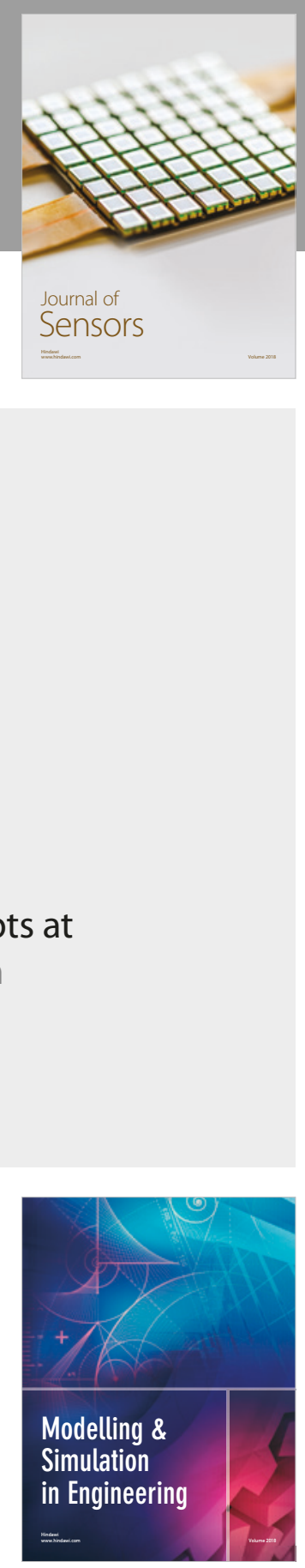

\section{Advances \\ Multimedia}
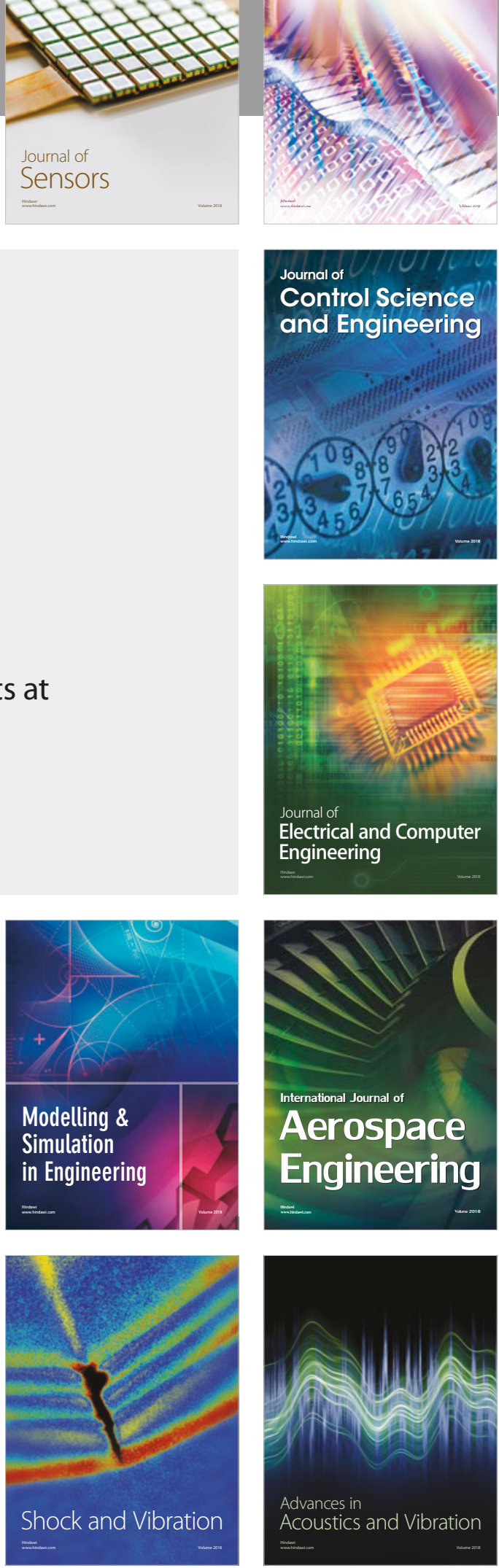